\title{
Effects of the Neuropeptide Substance P on Sleep, Mood, and Neuroendocrine Measures in Healthy Young Men
}

\author{
Klaus Lieb, Katrin Ahlvers, Katharina Dancker, Stefan Strohbusch, Martin Reincke, Bernd Feige, \\ Mathias Berger, Dieter Riemann, and Ulrich Voderholzer
}

The neuropeptide substance $P(S P)$ has been supposed to be involved in the etiopathology of affective disorders, mainly because of the finding of increased levels of SP in the cerebrospinal fluid of depressed patients and the preliminary evidence of antidepressant effects of SP-receptor antagonists in depressed patients. We investigated whether SP may induce changes of sleep, mood and neuroendocrine measures that are similar to those in depressed patients. In a double-blind, randomized cross-over design, 12 healthy young men were investigated in two blocks of three consecutive nights, in which $\mathrm{SP}$ or $\mathrm{NaCl}$ was intravenously infused during the third night. Polysomnographic recordings were obtained during all nights and blood samples were drawn every 30 min during the third night. Infusion of SP caused a significant worsening of the mood of the subjects, led to an increase of REM latency and time awake during the SP-infusion intervals, caused increased stage 1 sleep in the first part of the night, and led to increased cortisol and thyroid stimulating hormone levels and a trend for decreased growth hormone levels. These effects can be interpreted as evidence for a central arousing effect of SP. Further studies should focus on the effects of substance P in patients with depressive or other psychiatric disorders.

[Neuropsychopharmacology 27:1041-1049, 2002]

(C) 2002 American College of Neuropsychopharmacology. Published by Elsevier Science Inc.
KEY WORDS: Substance P; Sleep; Cortisol; Growth hormone; Depressive disorder; Neurokinin-1-receptor

Substance P (SP) is an undecapeptide which belongs to the neurokinin (tachykinin) family of peptides. SP-containing neurons are widely distributed in the periphery

From the Department of Psychiatry and Psychotherapy (KL, KA KD, SS, BF, MB, DR, UV), University of Freiburg Medical School, Hauptstr. 5, D-79104 Freiburg, Germany, and Department of Internal Medicine, Endocrinology Section (MR), University of Freiburg Medical School, Hugstetterstr. 55, D-79106 Freiburg, Germany.

Address correspondence to: Klaus Lieb, M.D., Department of Psychiatry and Psychotherapy, University of Freiburg Medical School, Hauptstr. 5, D-79104 Freiburg, Germany. Tel.: $(++49) 761 /$ 270-6501; Fax: (++49)761/270-6667; E-mail: klaus_lieb@psyallg. ukl.uni-freiburg.de

Received August 6, 2001; revised April 29, 2002; accepted May 6, 2002.

Online publication: 5/8/02 at www.acnp.org/citations/ Npp050802303. and the central nervous system (CNS), where they are found for example in the mid-brain and the basal ganglia, the hypothalamus and the limbic system including the hippocampus and amygdala (Pioro 1990). SP is colocalized with other neurotransmitters and has important neuromodulatory effects. Examples are co-localizations with serotonin in the raphe nucleus (Sergeyev et al. 1999), with dopamine in the midbrain and striatum, and with corticotropin releasing hormone $(\mathrm{CRH})$ in the hypothalamus (Otsuka and Yoshioka 1993). SP exerts its effects by binding to the neurokinin-1-receptor (NK1-R), which can be effectively blocked by specific NK-1$R$ antagonists (Kramer et al. 1998; Stout et al. 2001).

Because of its wide distribution and its neuromodulatory effects, SP has been supposed to be involved in the etiopathology of psychiatric disorders including schizophrenia, affective disorders, anxiety disorders and social phobia (Quartara and Maggi 1998; Rupniak 
and Kramer 1999; Stout et al. 2001). Hints for an involvement of SP in the pathology of depression and anxiety come from several animal studies. NK-1-R antagonists effectively blocked stress-induced vocalizations in guinea pig pups when separated from their mothers (Kramer et al. 1998) and showed antidepressant and anxiolytic activity in the chronic mild stress model (a model of depression; Papp et al. 2000) and the social interaction test (a model of anxiety; File 2000). Two recent studies in knockout mice for the NK-1-receptor have shown that the modulation of anxiety by the SP-system is at least in part mediated by the serotonergic system (Froger et al. 2001; Santarelli et al. 2001). In the first human study using a NK-1-R antagonist for the treatment of depression, the NK-1-R antagonist MK 869 showed potent antidepressant and anxiolytic activity (Kramer et al. 1998). Although human studies on substance P in anxiety disorders are lacking, two recent studies in parachute jumpers and civilians during a war attack have shown that subjects with high anxiety display elevated plasma SP levels (Schedlowski et al. 1995; Weiss et al. 1996). Altogether, these data suggest that SP may be of relevance in the etiopathology of affective and anxiety disorders and that NK-1-R antagonists may be a promising tool to treat such disorders.

SP challenge tests have been used to investigate possible effects of SP on CNS functions in healthy humans (Coiro et al. 1992a,b). It has been shown that SP given intravenously increases secretion of ACTH and cortisol in a dose dependent manner (Coiro et al. 1992a). This indicates that SP may exhibit centrally mediated neuroendocrine effects in humans.

In the present study, we were interested in possible effects of intravenously given SP on sleep and sleep-related neuroendocrine measures in humans. Following the hypothesis of SP as a "depressiogenic agent", our hypotheses were the following: (1) SP induces changes in sleep parameters which are similar to those found in depressed patients, i.e. disturbed sleep continuity, reduced slow wave sleep, shortening of REM-latency and increase in REM density (for overview see Berger and Riemann (1993) and Riemann et al. (2001)); and (2) SP leads to an increased cortisol- and a decreased sleep-associated growth hormone (GH)-secretion, which is also found in depressed patients (Steiger et al. 1993; Jarrett et al. 1990; Voderholzer et al. 1993).

\section{METHODS}

\section{Subjects}

Twelve healthy male subjects (age: 21 to 29 years) were recruited for this study through personal contact. Two subjects were excluded because of significant sleep disturbance during the baseline night. The remaining 10 subjects had a mean age of $26.5 \pm 2.8$ years. All subjects included were screened by routine laboratory parameters including an urine test, drug screening, ECG, EEG, physical and neurological examination and found to be in good physical health. Exclusion criteria were intake of any medication, more than $15 \%$ deviation from the ideal body weight, personal or family history of psychiatric disorders, history of alcohol or drug abuse, insomnia, or any other significant medical illness. Psychiatric disorders were ruled out by a psychiatric interview before inclusion into the study. Written informed consent was obtained before participation in the study. The experiments were performed in accord with the Helsinki Declaration of 1975 . The protocol was approved by the Ethical Committee of the University of Freiburg.

\section{Design}

The experiments were performed in a double-blind, randomized cross-over design. All subjects participated in a "SP-infusion" experimental session and in a "NaClinfusion" (placebo) control session. The study was carried out in the sleep laboratory of the Department of Psychiatry and Psychotherapy at the University of Freiburg. Each session consisted of three days, including three sleep polygraphic recordings: (1) adaptation, (2) baseline, (3) SP-infusion or NaCl-infusion. The two sessions were separated by at least one week. The first two polysomnograms served for adaptation to the sleep laboratory conditions and to obtain baseline sleep parameters. The third night was used to investigate effects of SP on sleep and neuroendocrine measures as compared with placebo ( $\mathrm{NaCl}$-infusion).

In the evening of the third night, at 7:00 P.M., an intravenous catheter was placed into an antecubital vein of the right arm, which served for both infusion of SP or $\mathrm{NaCl}$ and blood sampling. Synthetic SP (Clinalpha, Läufelfingen, Switzerland) or $\mathrm{NaCl}(0.9 \%)$ was infused intravenously for $20 \mathrm{~min}$. at four time points, one (10:30 P.M.) 30 min. before "lights out" (11:00 P.M.), and three times during sleep (11:30 P.M., 12:30 A.M., 1:30 A.M.). This application design was used since previous studies investigating effects of other neuropeptides on sleep parameters have shown that intermittent application may be more suitable than continuous infusion to detect subtle effects of these neuropeptides on sleep parameters (Steiger and Holsboer 1997). SP was given at a dose of $3 \mathrm{pmol} / \mathrm{kg}^{-1} / \mathrm{min}^{-1}$, a dose which has been shown to be well tolerated (Schaffalitzky De Muckadell et al. 1986). Blood samples were collected in the third night from 9:00 P.M. to 8:30 A.M. every $30 \mathrm{~min}$.

\section{Polysomnographic Assessments}

Sleep recordings were made on a 14 channel Nihon Kohden EEG polysomnograph from "lights out" (11:00 P.M.) to "lights on" (7:00 A.M.). All sleep recordings reg- 
istered EEG (C3-A2; C4-A1), ECG, horizontal and vertical EOG, and submental and leg EMG. During the adaptation night all subjects were screened for apneas and periodic leg movements by monitoring abdominal and thoracic effort, nasal airflow, oxymetry and bilateral tibialis anterior EMG. More than five apneas or hypopneas per hour or more than five periodic leg movements per hour were exclusion criteria. The following filter settings were used: EEG: sensitivity $7 \mu \mathrm{V} / \mathrm{mm}$, TC (time constant) $0.3 \mathrm{~s}$, HI (high frequency filter) $70 \mathrm{~Hz}$. EOG: sensitivity $30 \mu \mathrm{V} / \mathrm{mm}$, TC $2.0 \mathrm{~s}$, HI $35 \mathrm{~Hz}$; EMG: sensitivity $5 \mu \mathrm{V} / \mathrm{mm}$, TC $0.03 \mathrm{~s}$, HI $500 \mathrm{~Hz}$. Sleep EEG recordings were visually scored by experienced raters according to Rechtschaffen and Kales (1986) criteria. The raters were blind to the experimental conditions. Interrater reliability is checked bi-monthly in the sleep laboratory and concordance levels for all sleep stages range from $90-95 \%$ for five raters.

Sleep recordings were evaluated for parameters of sleep continuity and architecture, and REM sleep. Sleep continuity variables included: (1) sleep efficiency: ratio of total sleep time (TST) to time in bed (TIB) $\times 100 \%$ : (2) sleep onset latency: time from lights out until sleep onset (defined as first epoch of stage 2); (3) number of awakenings: at least one epoch of stage wake during sleep period time $(\mathrm{SPT}=$ time from sleep onset till the final awakening during the record).

Sleep architecture variables included: amounts of stages wake, 1, 2, 3, 4 and REM expressed as percentage of SPT. REM sleep variables were: (1) REM latency: time from sleep onset until the first epoch of REM sleep; (2) REM latency corrected: calculated by subtracting wake time between sleep onset and the first REM period from REM latency; (3) duration of the first REM period in $\mathrm{min}$; (4) total number of rapid eye movements during the whole night; (5) eye movement density of the first REM period in \%; (6) total REM density, i.e., eye movement density of all REM periods taken together in \% (REM density is defined as the ratio of $3 \mathrm{~s}$ mini-epochs per REM period including at least one rapid eye movement to the total number of 3-s miniepochs per REM sleep $\times 100 \%$ ).

\section{Psychometric and Behavioral Measurements}

To assess the quality of sleep, the following questionnaires were used: The Pittsburgh Sleep Quality Index (PSQI) (Buysse et al. 1989) served to exclude any sleep disturbance in the subjects prior to the study and was within the normal range ( $<5$ points) in all probands. The Sleep Questionnaire (SF-A; Görtelmeyer 1981) was completed after each night at 7:00 A.M. and assessed general sleep quality (range 1-5, with 1 denoting impaired sleep quality whereas a score of 5 indicates optimal sleep quality), feeling refreshed in the morning and psychosomatic complaints during the sleep phase.
To evaluate effects of SP on the mood of the subjects, the BF-S (Befindlichkeitsskala), an adjective mood scale with 28 items predominantly focusing on affective states (von Zerssen 1986) was completed in both blocks on night 1 at 10:00 P.M. and on night 3 directly after the first infusion as well as at 7:00 A.M. the following morning.

To assess possible peripheral effects of SP, the following parameters and symptoms were assessed in $2.5 \mathrm{~min}$ intervals during the first infusion (10:30 P.M.) of SP and $\mathrm{NaCl}$ : Systolic and diastolic blood pressure $(\mathrm{mmHg})$, pulse rate (beats $\times \min ^{-1}$ ), flushing of face, neck, arms, hands, conjunctival reddening, lacrimation, feeling of heat, headache, diarrhea, and abdominal colics (as estimated on a 10 point Likert Scale with $0=$ no symptoms and $9=$ very strong symptoms; see also Table 1 ).

\section{Neuroendocrine Measurements}

Blood was drawn in the infusion nights every $30 \mathrm{~min}$ from 9:00 P.M. until 8:30 A.M. and samples were used for measurements of serum cortisol, growth hormone (GH), and thyroid stimulating hormone (TSH). Because of its longer half life, TSH was only determined every $2 \mathrm{~h}$. All parameters were measured with specific chemoluminescence and enzyme-immuno assays on autoanalyzers (Nichols Advantage, Bad Nauheim, Germany (cortisol and GH) or Abbott Axsym (TSH). The limits of detection of cortisol, GH, and TSH assays were $0.3 \mu \mathrm{g} / \mathrm{dl}, 0.01 \mathrm{ng} / \mathrm{ml}$, and $0.06 \mu \mathrm{U} /$ $\mathrm{ml}$, respectively. The intraassay coefficients of variation are $5.3-9.1 \%$ for cortisol, $4.2-23.6 \%$ for $\mathrm{GH}$, and $3.1-10.8 \%$ for $\mathrm{TSH}$. The interassay coefficients of variation are $6.8-12.2 \%$ for cortisol, $4.1-12.1 \%$ for $\mathrm{GH}$, and $1.1-11.9 \%$ for TSH.

\section{Statistical Evaluation}

For descriptive purposes, means and standard deviations (SD) were calculated. The polysomnographic parameters as well as the psychic and behavioral effects of the "SP-infusion" session and the "NaCl-infusion" control session were compared by Student's $t$-test for dependent samples, and if the data were not normally distributed, by non-parametric tests (Wilcoxon test) for dependent samples. For assessment of neuroendocrine measures, area under the curves (AUCs) were calculated as the sum of all concentration values within the selected time interval (the first and the last value divided by two) multiplied by the sampling interval $(0.5$ h). The level of significance was set at $p \leqslant .05$.

\section{RESULTS}

\section{Effects on Mood and Behavioral Effects of SP-infusion}

Intravenous infusion of SP caused peripheral effects which were due to the vasodilatative properties of SP. 
Table 1. Maximum values \pm SD for blood pressure, pulse rate, flushing and other symptoms induced by SP during the first $20 \mathrm{~min}$-infusion at $22.30 \mathrm{~h}$ as compared to baseline levels before the infusion and the $\mathrm{NaCl}$-infusion. Flushing and other symptoms were rated on a 10 point Likert Scale $(0=$ no symptoms and $9=$ very strong symptoms $)$.

\begin{tabular}{|c|c|c|c|c|c|}
\hline Parameter & & $\mathrm{NaCl}$-infusion & SP-infusion & $\begin{array}{c}\text { Number of } \\
\text { subjects } \\
\text { with symptoms } \\
\text { during SP }\end{array}$ & $\begin{array}{c}\text { Statistics } \mathrm{NaCl} \\
\text { vs. SP }\end{array}$ \\
\hline \multirow[t]{2}{*}{ Systolic RR (mmHg) } & Before & $121.5 \pm 9.7$ & $125.7 \pm 9.0$ & & n.s. \\
\hline & During & $130.3 \pm 8.7$ & $138.0 \pm 10.6$ & & $p<.05$ \\
\hline \multirow[t]{2}{*}{ Diastolic RR (mmHg) } & Before & $74.7 \pm 9.1$ & $68.2 \pm 5.9$ & & n.s. \\
\hline & During & $73.8 \pm 6.0$ & $68.4 \pm 8.6$ & & n.s. \\
\hline \multirow[t]{2}{*}{ pulse rate (beats $x \mathrm{~min}^{-1}$ ) } & Before & $61.8 \pm 7.8$ & $60.0 \pm 12.2$ & & n.s. \\
\hline & During & $63.1 \pm 10.8$ & $90.1 \pm 10.2^{*}$ & & $p<.001$ \\
\hline \multirow[t]{2}{*}{ Flushing } & Before & 0 & 0 & & \\
\hline & During & 0 & $7.1 \pm 1.5^{* *}$ & 10 & $p<.01[\mathrm{~W}]$ \\
\hline \multirow[t]{2}{*}{ Conjunctival reddening } & Before & 0 & 0 & & \\
\hline & During & 0 & $4.9 \pm 2.0^{* *}$ & 10 & $p<.01[\mathrm{~W}]$ \\
\hline \multirow[t]{2}{*}{ Lacrimation } & Before & 0 & 0 & & \\
\hline & During & 0 & $2.6 \pm 2.9^{*}$ & 4 & $p<.05[\mathrm{~W}]$ \\
\hline \multirow[t]{2}{*}{ feeling of heat } & Before & 0 & 0 & & \\
\hline & During & 0 & $6.1 \pm 2.8^{* *}$ & 9 & $p<.01[\mathrm{~W}]$ \\
\hline \multirow[t]{2}{*}{ Headache } & Before & 0 & 0 & & \\
\hline & During & 0 & $0.9 \pm 1.4$ & 4 & n.s. [W] \\
\hline \multirow[t]{2}{*}{ Diarrhea } & Before & 0 & 0 & & \\
\hline & During & 0 & $0.8 \pm 2.5$ & 1 & n.s. [W] \\
\hline \multirow[t]{2}{*}{ Abdominal colics } & Before & 0 & 0 & & \\
\hline & During & 0 & $0.2 \pm 0.6$ & 1 & n.s. [W] \\
\hline
\end{tabular}

${ }^{*} p<.05 ;{ }^{* *} \mathrm{p}<0.01$ (baseline vs. Infusion); [W] Wilcoxon asymptotic significance

Flushing of face and neck and other symptoms were observed 1-2 min. after start of the infusion and disappeared after further 5-10 min in spite of a constant infusion rate. Table 1 gives maximum scores of various parameters/symptoms assessed in $2.5 \mathrm{~min}$ intervals during the first infusion (10:30-10:50 P.M.) of SP (NaClinfusion did not cause significant changes in the parameters). Elevation of pulse rate, systolic blood pressure and flushing were the most prominent symptoms, which were well tolerated by the subjects. Pulse rate and systolic blood pressure were significantly increased (Table 1). Feeling of heat and conjunctival reddening as well as headache were less pronounced. Diarrhea appeared in only one subject.

Mean values on the BF-S (von Zerssen 1986), a scale with 28 items predominantly focusing on mood states, were within the normal range (5-16 pts.) at all time points. However, whereas $\mathrm{NaCl}$-infusion did not cause significant changes in the subjective well-being, mood was impaired directly after SP-infusion (14.2 \pm 5.7 after vs. $8.3 \pm 4.2$ before infusion, $p<.05)$ and possibly after the night of SP-infusion ( $15.0 \pm 8.0$ after vs. $8.3 \pm 4.2$ before infusion, $p=.07)$. By further investigating which symptoms contributed most significantly to this change, we found a significant change of items resembling most closely depression (feeling unhappy, melancholic, depressed), but not items resembling fatigue or agitation, for example. Depressive symptoms (feeling unhappy, melancholic, depressed) significantly increased directly after SP-infusion $(0.1 \pm 0.3$ vs. $1.1 \pm$ $1.2 ; p<.05)$ and were still significantly elevated the morning after the SP-infusion night $(1.2 \pm 1.3 ; p<.05)$. Depressive symptoms directly after SP-infusion were also significantly elevated as compared with the saline control infusion $(1.1 \pm 1.2$ vs. $0.3 \pm 0.7 ; p<.05)$.

\section{Effects of SP on Sleep Parameters}

Infusion of SP significantly influenced sleep, as documented by both polysomnography and subjective rating scales. There was a significant decrease of sleep quality as assessed by the SFA $(3.3 \pm 0.7$ in the NaClinfusion night vs. $2.7 \pm 0.5$ in the SP-infusion night; $p<$ $.05)$ and a significant increase of "psychosomatic complaints" during the sleep phase $(1.6 \pm 0.6$ in NaCl-infusion night vs. $1.9 \pm 0.5$ in the SP-infusion night; $p<.05)$. Table 2 shows the values of the various polysomnographic parameters for the whole night of $\mathrm{SP}$ and $\mathrm{NaCl}$ infusion. Only REM latency was different between nights with an increase in the SP-infusion night. Since SP was infused only during the first half of the night, we further investigated possible effects of SP on sleep by a separate analysis of the first and second half of the night. This analysis showed a significant increase of stage 1 sleep in the first half of the night ( $8 \pm 4.6 \%$ vs. $5.9 \pm 4.5 \%$ for the SP-infusion night and the $\mathrm{NaCl}$-infu- 
sion night, respectively) and a significant decrease of REM density in the second half of the night (19.3 \pm $5.4 \%$ vs. $24.2 \pm 2.5 \%$ in the SP-infusion night and the $\mathrm{NaCl}$-infusion night, respectively). Since we assumed that SP might disturb sleep by an arousing effect, we calculated the "time awake" during the three SP-infusion intervals during the night, which was significantly longer than the "time awake" during the $\mathrm{NaCl}$-infusion intervals (32.2 \pm 29.0 vs. $10.5 \pm 13.9 \mathrm{~min}, p<.05)$. The number of periods awake during the total night and \% awake of total sleep period was, however, not significantly different between both infusion nights (Table 2).

\section{Effects of SP on Neuroendocrine Measures}

Mean cortisol concentrations during the total night are given in Figure 1, panel A. The first infusion of SP at 10:30 P.M. caused a significant increase in serum cortisol levels at 11:00 P.M. as compared with the $\mathrm{NaCl}$-infusion, which did not change cortisol levels $(p<.05$; see Figure 1, panel A). The AUCs for cortisol in the total SP-infusion night were significantly higher than the AUCs in the $\mathrm{NaCl}$-infusion night $(7.3 \pm 1.5$ vs. $5.7 \pm 1.7 \mu \mathrm{g} / \mathrm{dl} /$ $h$, respectively, $p<.01$ ).

This was due to a significant difference of the AUCs in the first half of the night (10:30 P.M. to 2:30 A.M.) with $5.1 \pm$ $2.9 \mu \mathrm{g} / \mathrm{dl} / \mathrm{h}$ cortisol in the SP-infusion night and $3.0 \pm 1.5$ $\mu \mathrm{g} / \mathrm{dl} / \mathrm{h}$ cortisol in the $\mathrm{NaCl}$-infusion night $(p<.05$; see Figure 1, panel A), whereas AUCs of cortisol were not different in the second half of the night. Individual cortisol maxima were not different between the SP-infusion night and the $\mathrm{NaCl}$-infusion-night, but cortisol minima in the SP-infusion-night were higher than in the $\mathrm{NaCl}$-infusion night $(2.3 \pm 1.0$ vs. $1.7 \pm 0.8 \mu \mathrm{g} / \mathrm{dl}$, respectively, $p<.01)$. We further evaluated whether the increase of pulse rate during the SP-infusion might explain the increase in cortisol levels. Although the maximal pulse rate during the SP-infusions did not correlate with the AUCs for cortisol between 10:30 P.M. and 2:00 A.M., the increase in pulse rate between baseline and maximal pulse rate was significantly correlated with the increase between baseline cortisol and maximal cortisol levels $(r=0.36 ; p<.01)$.

Values for GH are given in Figure 1, panel B. Although not significant, maximal levels of $\mathrm{GH}$ tended to be lower during the SP-infusion night as compared with the $\mathrm{NaCl}$-infusion night $(8.2 \pm 4.3$ vs. $12.8 \pm 9.1$ $\mathrm{ng} / \mathrm{ml}$, respectively, $p=.08$ ). Also the AUCs for GH of the total night tended to be lower in the SP-infusion night as compared with the placebo-night $(1.5 \pm 0.8 \mathrm{vs}$. $2.8 \pm 2.4 \mathrm{ng} / \mathrm{ml} / \mathrm{h}$, respectively, $p=.09$ ).

AUCs for TSH were significantly higher in the total SP-infusion night as compared with the $\mathrm{NaCl}$-infusion night ( $2.1 \pm 1.1$ vs. $1.7 \pm 0.7 \mu \mathrm{U} / \mathrm{ml}$, respectively, $p<$ .05 ; see Figure 1, panel C).

\section{DISCUSSION}

We have shown that infusion of SP in healthy young men caused a significant worsening of the mood of the subjects, increased REM latency, time awake during the SP-infusion intervals, and stage 1 sleep in the first part of the night and decreased REM density in the second part of the night. Furthermore, SP-infusion significantly increased cortisol and TSH levels and led to a trend for decreased GH levels. Some of the effects, namely increased cortisol and decreased GH levels as well as the worsening of mood might be relevant with respect to the etiopathology of depressive disorders.

We used four blocks of SP-infusion over 20 min each instead of a constant infusion rate, because earlier studies investigating the effects of neuropeptides on sleep (see Steiger and Holsboer (1997) for review) have shown that small effects of these substances on sleep related parameters may be missed with a constant infu-

Table 2. Sleep parameters during the total night of SP- and $\mathrm{NaCl}$-infusion.

\begin{tabular}{lccc}
\hline Sleep Parameter & NaCl-infusion & SP-infusion & Statistics \\
\hline Total sleep time (min.) & $414 \pm 36$ & $403 \pm 51$ & n.s. \\
Sleep onset latency (min.) & $34 \pm 28$ & $30 \pm 17$ & n.s. \\
Sleep efficiency index (\%) & $86 \pm 8$ & $84 \pm 11$ & n.s. \\
REM-latency (min.) & $69 \pm 27$ & $113 \pm 50$ & $p<.05$ \\
REM-latency corrected (min.) & $66 \pm 24$ & $85 \pm 27$ & $21 \pm 5$ \\
Total REM-density (\%) & $22 \pm 8$ & $17.0 \pm 12.3$ & n.s. \\
Duration of 1. REM period (min) & $10.4 \pm 4.8$ & $378 \pm 114$ & n.s. \\
Total No. of eye movements & $406 \pm 159$ & $10.1 \pm 8.6$ & n.s. \\
\% awake of sleep period & $6.7 \pm 6.2$ & $24.8 \pm 9.9$ & n.s. \\
No. of waking periods & $18.7 \pm 11.6$ & $8.4 \pm 3.8$ & n.s. \\
\% stage 1 of sleep period & $7.6 \pm 4.6$ & $52.3 \pm 8.8$ & n.s. \\
\% stage 2 of sleep period & $55.1 \pm 8.5$ & $7.9 \pm 6.0$ & n.s. \\
$\%$ stage 3 + 4 of sleep period & $9.1 \pm 6.2$ & $20.8 \pm 4.4$ & n.s. \\
\% REM of sleep period & $21.0 \pm 5.2$ & n.s. \\
\hline
\end{tabular}




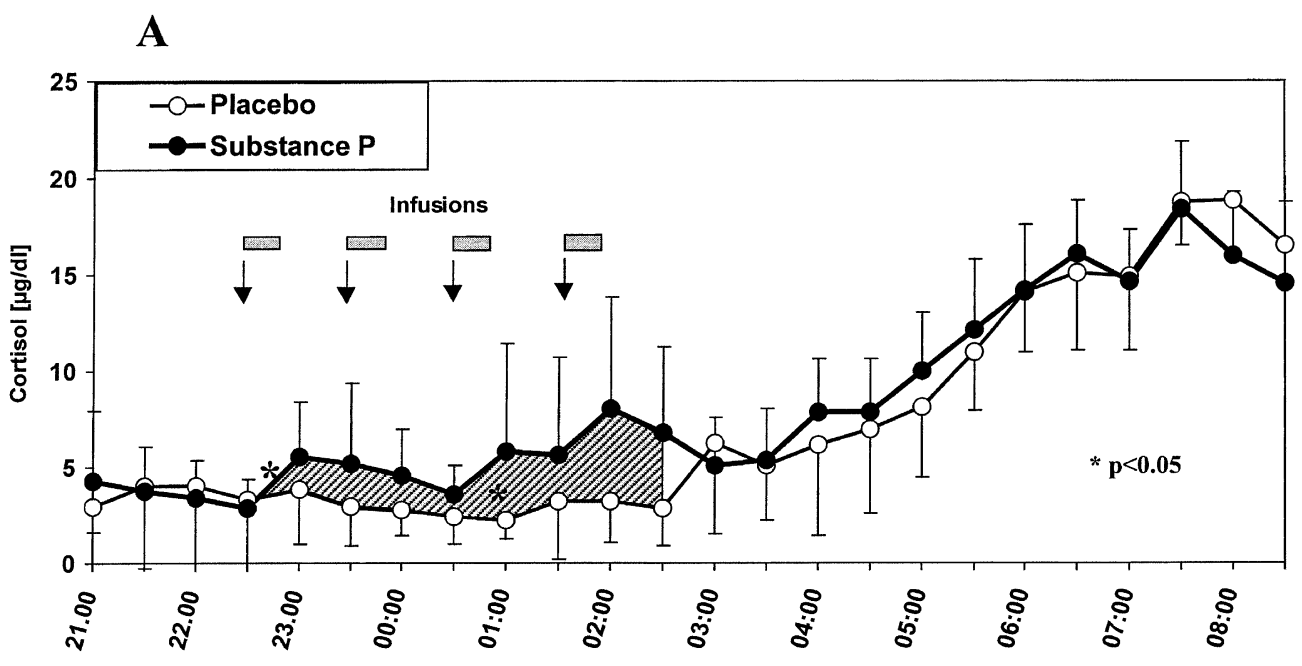

B
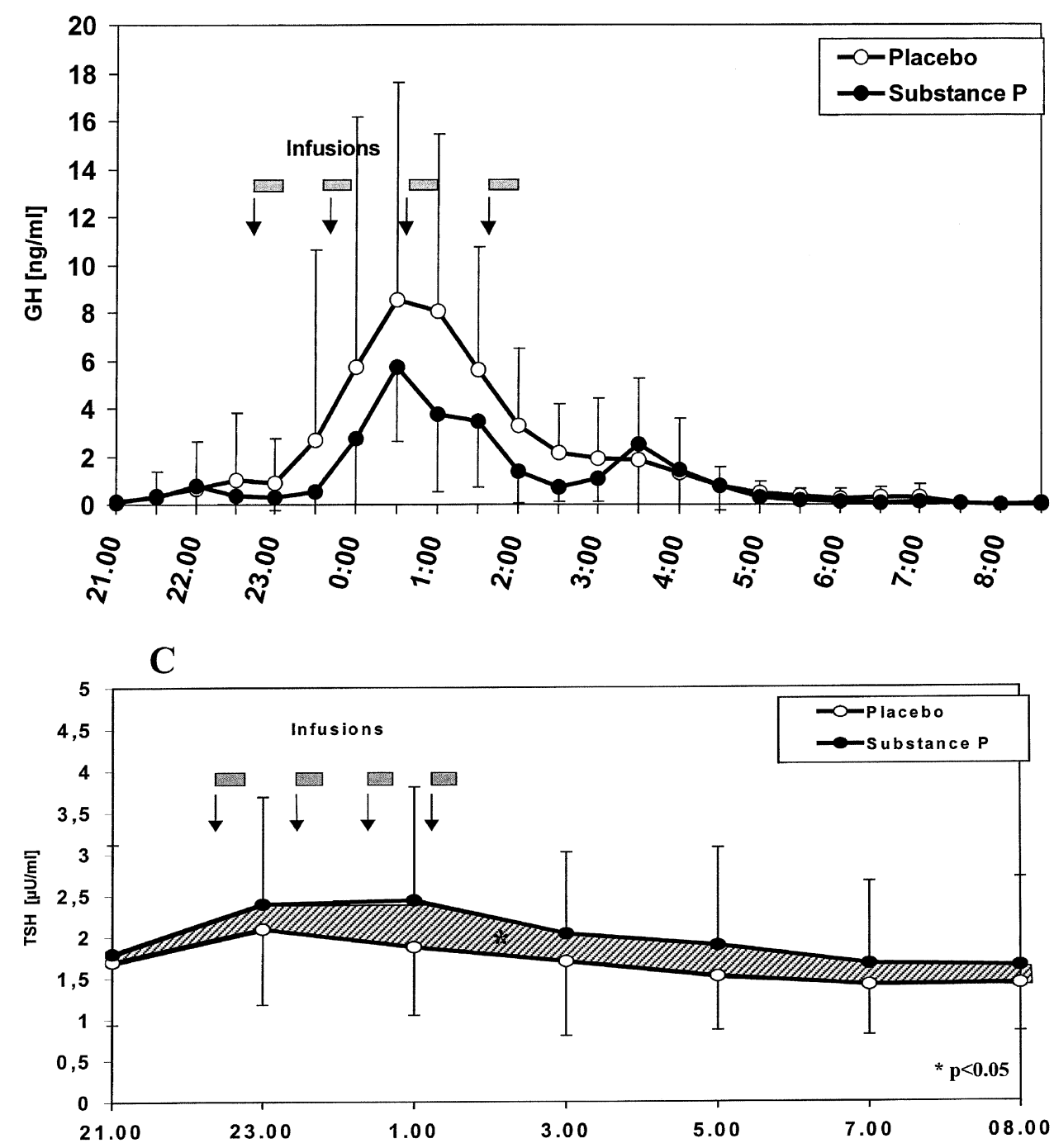

Figure 1. A. Serum cortisol $(\mu \mathrm{g} / \mathrm{dl})$ during the night of SP-infusion $(\bullet)$ as compared with the $\mathrm{NaCl}$ (placebo) infusion $(O)$. Blood samples were taken every $30 \mathrm{~min}$ from 9:00 P.M. until 8:30 A.M. the following morning. Time periods of infusions are indicated by bars and arrows. Values are mean \pm SD. The marked area indicates a significant difference in the AUC between SP-infusion and saline control. 
sion rate. SP was given at a dose of $3 \mathrm{pmol} / \mathrm{kg}^{-1} / \mathrm{min}^{-1}$, which was quite well tolerated by our subjects. Earlier studies have used doses up to $16 \mathrm{pmol} / \mathrm{kg}^{-1} / \mathrm{min}^{-1}$, which similarly as in our study caused flushing, but were otherwise well tolerated by the subjects (Schaffalitzky De Muckadell et al. 1986). Coiro et al. (1992a) used doses between 0.5 and $1.5 \mathrm{pmol} / \mathrm{kg}^{-1} / \mathrm{min}^{-1}$ given over $60 \mathrm{~min}$, of which even the infusion of $1 \mathrm{pmol} / \mathrm{kg}^{-1} /$ $\mathrm{min}^{-1}$ showed significant biological effects, as demonstrated by a significant rise of ACTH and cortisol levels.

Despite an even higher SP-concentration as compared with the study of Coiro et al. (1992a,b), the effects on mood, sleep parameters and neuroendocrine measures were rather small in our study. Of all sleep parameters for the total night, only REM latency significantly increased and REM density significantly decreased in the second half of the night. These changes were contradictory to our hypothesis that SP causes changes in sleep parameters similar to the finding in depressed patients, i.e. shortening of REM latency and increase of REM density (see Berger and Riemann 1993, Riemann et al. 2001). Since REM latency is a very sensitive sleep parameter, which can be easily disturbed by unspecific stressors (see for example Lauer et al. (1987)), we cannot exclude that the increase of REM latency is due to an unspecific disturbance of sleep induced by SP. Such an unspecific cause of sleep disturbance might be the SP-induced elevation of pulse rate, which might also have caused increased stage 1 sleep in the first part of the night and increased time awake during the SP-infusion intervals. However, pulse rate was not correlated to any sleep parameter assessed. To answer this question, a comparative analysis of different SP-fragments which do or do not contain the domain mediating the tachykinin-like effects would be necessary.

The effects on neuroendocrine measures were also relatively small as compared with the effects which Coiro et al. (1992a,b) found even with lower doses. This difference might be explained by the different time points at which SP was administered. In contrast to our study, in the studies of Coiro et al. on SP-induced ACTH- and cortisol-secretion (Coiro et al. 1992a) and SP-induced GH-secretion (Coiro et al. 1992b), SP was administered at 9:00 A.M. Nevertheless, our results confirm the finding of Coiro et al. (1992a) that SP stimulates cortisol secretion. This increment is probably due to a central effect of SP since increased cortisol levels went in parallel with an increase in ACTH secretion in the study of Coiro et al. (1992a). It might be speculated that activation of the HPA axis by SP plays a role in the pathogenesis of the hypercortisolism often seen in depressed patients (Holsboer 1995; Linkowski et al. 1987), but this cannot definitively be answered from this study, in which we measured acute effects of SP in healthy subjects. Further studies should investigate effects of SP on ACTH and cortisol secretion in depressed patients. Our finding of a trend for lower levels of $\mathrm{GH}$ during the SP-infusion night is in contrast to the study of Coiro et al. (1992b) who found that SP enhances basal and GHRH-stimulated GH secretion in normal men. This result could again be due to the different application time points (during the night in our study and in the morning in the study of Coiro et al. 1992b). Our result of a sleep-associated blunting of $\mathrm{GH}$-secretion by $\mathrm{SP}$, however, is similar to the finding of disturbed GHsecretion in depressed patients (Jarrett et al. 1990; Steiger et al. 1993; Voderholzer et al. 1993). However, because we found a trend but not a significant effect of SP on GH-secretion, further studies in healthy subjects and in depressive patients are necessary to prove whether SP influences the growth hormone axis.

Since SP and CRH have been shown to be colocalized in the hypothalamus (Otsuka and Yoshioka 1993), it might be speculated that SP exerts its effects by stimulating CRH secretion. Previous studies have shown that CRH has similar effects on sleep and neuroendocrine measures as SP as demonstrated here, i.e. decrease of REM and increase of stage 1 and 2 sleep as well as increase of cortisol secretion and blunting of sleep-related GH release (Born et al. 1989; Holsboer et al. 1988).

The effects of SP on mood states of our subjects were most pronounced directly after the infusion. SP did not induce clinically relevant symptoms such as depressive states or panic attacks, but caused a significant worsening of mood of our subjects. This effect was mostly be due to a significant change in items resembling most closely depression (feeling unhappy, melancholic, depressed), but not in items resembling e.g. fatigue or agitation. Further studies should investigate effects of SP on mood and anxiety with longer infusion intervals, lower doses which do not induce noticable side effects and in patients suffering from depression and anxiety disorders.

Figure 1 Continued. B. Serum growth hormone $(\mathrm{GH})(\mathrm{ng} / \mathrm{ml})$ during the night of SP-infusion $(\mathbf{O})$ as compared with the $\mathrm{NaCl}$ (placebo) infusion (○). Blood samples were taken every 30 min from 9:00 P.M. until 8:30 A.M. the following morning. Time periods of infusions are indicated by bars and arrows. Values are mean \pm SD.

C. Serum TSH $(\mu \mathrm{U} / \mathrm{ml})$ during the night of SP-infusion $(\bullet)$ as compared with the $\mathrm{NaCl}$ (placebo) infusion $(\bigcirc)$. Blood samples were measured every $2 \mathrm{~h}$ from 9:00 P.M. until 8:00 A.M. the following morning. Time periods of infusions are indicated by bars and arrows. Values are mean \pm SD. The marked area indicates a significant difference in the AUC between SP-infusion and saline control. 
In conclusion, we have shown that infusion of SP has significant biological and behavioral effects in healthy young men as demonstrated by significant changes of mood, sleep parameters and neuroendocrine measures. These effects can be interpreted as evidence for a central arousing effect of SP. Although we believe that the effects of SP are due to direct central effects, this study cannot exclude the possibility that the results we found in sleep and neuroendocrine parameters are the consequence of the subjects feeling stressed of uncomfortable during the infusion of SP, that is, the consequence of effects of the peptide in the periphery. Further studies will focus on effects of SP in patients with affective or anxiety disorders to investigate whether SP may induce mood changes in these patients or may be able to induce panic attacks. Furthermore, by using different SPfragments, it will be investigated whether the effects of SP seen in our study can be separated from the tachykinin-like effects of the substance.

\section{ACKNOWLEDGMENTS}

We would like to thank Dr. Gesa Weske for her help in subject's care and data analysis.

\section{REFERENCES}

Berger M, Riemann D (1993): Normal and abnormal REM sleep regulation: REM sleep in depression-an overview. J Sleep Res 2:211-223

Born J, Spath-Schwalbe E, Schwakenhofer H, Kern W, Fehm HL (1989): Influences of corticotropin-releasing hormone, adrenocorticotropin, and cortisol on sleep in normal man. J Clin Endocrinol Metab 68:904-911

Buysse DJ, Reynolds CF III, Monk TH, Berman SR, Kupfer DJ (1989): The Pittsburgh Sleep Quality Index: a new instrument for psychiatric practice and research. Psychiatry Res 28:193-213

Coiro V, Capretti L, Volpi R, Davoli C, Marcato A, Cavazzini U, Caffarri G, Rossi G, Chiodera P (1992a): Stimulation of ACTH/cortisol by intravenously infused substance P in normal men: inhibition by sodium valproate. Neuroendocrinology 56:459-463

Coiro V, Volpi R, Capretti L, Speroni G, Bocchi R, Caffarri G, Colla R, Rossi G, Chiodera P (1992b): Intravenously infused substance $\mathrm{P}$ enhances basal and growth hormone $(\mathrm{GH})$ releasing hormone-stimulated GH secretion in normal men. Peptides 13:843-846

File SE (2000): NKP608, an NK1 receptor antagonist, has an anxiolytic action in the social interaction test in rats. Psychopharmacology (Berl) 152:105-109

Froger N, Gardier AM, Moratalla R, Alberti I, Lena I, Boni C, De Felipe C, Rupniak NM, Hunt SP, Jacquot C, Hamon M, Lanfumey L (2001): 5-hydroxytryptamine (5-HT)1A autoreceptor adaptive changes in substance P (neurokinin 1) receptor knock-out mice mimic antidepressantinduced desensitization. J Neurosci 21:8188-8197
Görtelmeyer R (1981): On the development of a standardized sleep inventory for the assessment of sleep. In Kubicki S and Herrmann WM (eds), Methods of Sleep Research. Stuttgart, Germany, Gustav Fischer, pp 93-98

Holsboer F (1995) Neuroendocrinology of mood disorders. Psychopharmacology 957-970

Holsboer F, von Bardeleben U, Steiger A (1988): Effects of intravenous corticotropin-releasing hormone upon sleep-related growth hormone surge and sleep EEG in man. Neuroendocrinology 48:32-38

Jarrett DB, Miewald JM, Kupfer DJ (1990): Recurrent depression is associated with a persistent reduction in sleeprelated growth hormone secretion. Arch Gen Psychiatry 47:113-118

Kramer MS, Cutler N, Feighner J, Shrivastava R, Carman J, Sramek JJ, Reines SA, Liu G, Snavely D, Wyatt-Knowles E, Hale JJ, Mills SG, MacCoss M, Swain CJ, Harrison T, Hill RG, Hefti F, Scolnick EM, Cascieri MA, Chicchi GG, Sadowski S, Williams AR, Hewson L, Smith D, Rupniak NM (1998): Distinct mechanism for antidepressant activity by blockade of central substance $\mathrm{P}$ receptors. Science 281:1640-1645

Lauer C, Riemann D, Lund R, Berger M (1987): Shortened REM latency: a consequence of psychological strain? Psychophysiology 24:263-271

Linkowski P, Mendlewicz J, Kerkhofs M, Leclercq R, Golstein J, Brasseur M, Copinschi G, Van Cauter E (1987): 24-hour profiles of adrenocorticotropin, cortisol, and growth hormone in major depressive illness: effect of antidepressant treatment. J Clin Endocrinol Metab 65:141-152

Otsuka M, Yoshioka K (1993): Neurotransmitter functions of mammalian tachykinins. Physiol Rev 73:229-308

Papp M, Vassout A, Gentsch C (2000): The NK1-receptor antagonist NKP608 has an antidepressant-like effect in the chronic mild stress model of depression in rats. Behav Brain Res 115:19-23

Pioro EP (1990): Distribution of substance P and enkephalin immunoreactive neurons and fibers. In Paxinos G (ed), The Human Nervous System. San Diego, New York, Academic Press, pp 1051-1094

Quartara L, Maggi CA (1998): The tachykinin NK1 receptor. Part II: Distribution and pathophysiological roles. Neuropeptides 32:1-49

Rechtschaffen A, Kales A (1986): A manual of standardized terminology, techniques and scoring system for sleep stages of human subjects. Washington D.C., US Government Printing Office

Riemann D, Berger M, Voderholzer U (2001): Sleep and depression - results from psychobiological studies: An overview. Biol Psychol 57:67-103

Rupniak NM, Kramer MS (1999): Discovery of the antidepressant and anti-emetic efficacy of substance $P$ receptor (NK1) antagonists. Trends Pharmacol Sci 20:485-490

Santarelli L, Gobbi G, Debs PC, Sibille ET, Blier P, Hen R, Heath MJ (2001): Genetic and pharmacological disruption of neurokinin 1 receptor function decreases anxiety-related behaviors and increases serotonergic function. Proc Natl Acad Sci USA 98:1912-1917

Schaffalitzky De Muckadell OB, Aggestrup S, Stentoft P (1986): Flushing and plasma substance P concentration 
during infusion of synthetic substance P in normal man. Scand J Gastroenterol 21:498-502

Schedlowski M, Fluge T, Richter S, Tewes U, Schmidt RE, Wagner TO (1995): Beta-endorphin, but not substance$\mathrm{P}$, is increased by acute stress in humans. Psychoneuroendocrinology 20:103-110

Sergeyev V, Hokfelt T, Hurd Y (1999): Serotonin and substance $\mathrm{P}$ co-exist in dorsal raphe neurons of the human brain. Neuroreport 10:3967-3970

Steiger A, Holsboer F (1997): Neuropeptides and human sleep. Sleep 20:1038-1052

Steiger A, von Bardeleben U, Guldner J, Lauer C, Rothe B, Holsboer F (1993): The sleep EEG and nocturnal hormonal secretion studies on changes during the course of depression and on effects of CNS-active drugs. Prog Neuropsychopharmacol Biol Psychiatry 17: 125-137

Stout SC, Owens MJ, Nemeroff CB (2001) Neurokinin(1) receptor antagonists as potential antidepressants. Annu Rev Pharmacol Toxicol 41:877-906

Voderholzer U, Laakmann G, Wittmann R, Daffner-Bujia C, Hinz A, Haag C, Baghai T (1993): Profiles of spontaneous 24-hour and stimulated growth hormone secretion in male patients with endogenous depression. Psychiatry Res 47:215-227

von Zerssen D (1986): Clinical Self-rating scales (CSRS) of the Munich Psychiatry Information System (PSYCHIS München). In Sartorius N, Ban T (eds.), Assessment of Depression. Berlin, New York, Springer-Verlag, pp 270 303

Weiss DW, Hirt R, Tarcic N, Berzon Y, Ben-Zur H, Breznitz S, Glaser B, Grover NB, Baras M, O’Dorisio TM (1996): Studies in psychoneuroimmunology: psychological, immunological, and neuroendocrinological parameters in Israeli civilians during and after a period of Scud missile attacks. Behav Med 22:5-14 